\title{
Terras de Ouro: Narrativas e experiências indígenas e não indígenas acerca do garimpo de ouro na Amazônia Brasileira
}

Gold Lands: Indigenous and non-indigenous narratives and experiences about gold mining in the Brazilian Amazon

\section{Aline Fonseca lubel}

\section{(2) OpenEdition Journals}

\section{Edição electrónica}

URL: https://journals.openedition.org/aa/4995

DOI: 10.4000/aa.4995

ISSN: 2357-738X

\section{Editora}

Programa de Pós-Graduação em Antropologia Social (UnB)

\section{Edição impressa}

Paginação: 289-305

ISSN: 0102-4302

\section{Refêrencia eletrónica}

Aline Fonseca lubel, «Terras de Ouro: Narrativas e experiências indígenas e não indígenas acerca do garimpo de ouro na Amazônia Brasileira», Anuário Antropológico [Online], v.45 n.1 | 2020, posto online no dia 27 janeiro 2020, consultado o 22 julho 2022. URL: http://journals.openedition.org/aa/4995 ; DOI: https://doi.org/10.4000/aa.4995

\section{(c) (i) (9)}

Creative Commons - Atribuição-NãoComercial-SemDerivações 4.0 Internacional - CC BY-NC-ND 4.0 https://creativecommons.org/licenses/by-nc-nd/4.0/ 


\title{
Terras de Ouro: Narrativas e experiências indígenas e não indígenas acerca do garimpo de ouro na Amazônia Brasileira
}

\author{
Gold Lands: Indigenous and non-indigenous narratives and experiences \\ about gold mining in the Brazilian Amazon \\ DOI: https://doi.org/10.4000/aa.4995
}

\begin{abstract}
Aline Fonseca Iubel • Universidade Estadual de Campinas - Brasil
Pós-doutora em Antropologia (Unicamp), com pesquisa sobre territorialidades no Alto Rio Negro. Doutora em Antropologia Social (UFSCar), com tese sobre movimento indígena e política partidária no município de São Gabriel da Cachoeira. Mestre em Antropologia Social e bacharel em Ciências Sociais (UFPR).
\end{abstract}

Este artigo realiza algumas comparações entre diferentes perspectivas - indígenas e não indígenas - acerca do ouro e sua garimpagem na Amazônia Brasileira. O principal objetivo é contribuir para os debates da área conhecida como "antropologia da mineração" apresentando perspectivas locais acerca desta atividade de exploração mineral, há muito praticada na Amazônia. São elencados dados bibliográficos e etnográficos sobre as relações que os Yanomami, os Waiãpi, povos indígenas do Alto Rio Negro e garimpeiros não indígenas estabelecem com os garimpos de ouro desde os anos 1970. A análise comparativa de diferentes experiências e narrativas permitiu esboçar algumas reflexões acerca de críticas locais que são feitas à atividade garimpeira e à extração do ouro. Críticas cujos fundamentos são encontrados em formas particulares de se conceber tal metal, que podem envolver desde a centralidade do ouro na composição da Terra como algo perene e durável até os perigos políticos e cosmológicos decorrentes da exploração aurífera, passando por concepções acerca das distâncias seguras que se deve manter ou não em relação ao ouro..

Ouro. Garimpo. Indígenas. Não indígenas. Amazônia brasileira
This article does some comparisons between different perspectives indigenous and nonindigenous - about gold and its mining in the Brazilian Amazon. The main objective is to contribute to the debates of an area known as "mining anthropology" with local perspectives on this activity of mineral exploration long practiced in the Amazon. Bibliographical and ethnographic data on the relationships that the Yanomami, Waiãpi, indigenous peoples of the upper Rio Negro and non-indigenous gold miners establish with gold mining since the 1970 s are listed. The comparative analysis of different experiences and narratives allowed us to sketch some reflections about the criticisms that are made locally of the gold mining activity and the extraction of gold. Criticisms whose foundations are found in particular ways of conceiving such a metal, which may range from the centrality of gold in the composition of the earth as perennial and durable, to the political and cosmological dangers arising from gold exploration, and to the conception of safe distances must keep or not in relation to it.

Gold. Small-scale gold mining. Indigenous. Non-Indigenous. Brazilian Amazon. 
Metais (preciosos ou não) são prospectados e explorados por, pelo menos, três motivos: para serem usados na confecção de adornos, ornamentos e objetos de luxo, símbolos de riqueza (relação que é tanto simbólica quanto material); para a produção de objetos e instrumentos da vida cotidiana; e na constituição de lastro para transações comerciais ${ }^{1}$. Para além de suas finalidades, valores e usos, rochas, pedras e metais podem servir também como marcadores temporais. De um lado, algumas formas científicas (ocidentais) de classificação e datação da Terra e da Humanidade, por exemplo, estabelecem termos como Idade da Pedra, do Bronze e do Ferro ${ }^{2}$. De outro, em alguns corpora de conhecimentos indígenas, a existência ou não de metais e rochas na composição material do mundo também é definidora de tempos e possibilidades de vida. Em ambos os casos, o acesso ou não a instrumentos obtidos a partir da manufatura desses materiais transforma as atividades e vidas das pessoas ${ }^{3}$.

Ainda que os custos ambiental, humano e social da exploração desses materiais não sejam pequenos, em regimes nos quais a acumulação de riquezas conta mais que preservação ambiental ou relações interespecíficas, por exemplo, eles não bastam para frear ou desacelerar os avanços de empreendimentos que visem incrementar a economia ${ }^{4}$. Esta espécie de licença para atividades depredatórias baseia-se em concepções particulares da Terra como provedora de recursos a serem explorados e transformados em mercadoria. Mas, existem outros modos de se conceber tanto a composição da Terra quanto as relações que se estabelecem com o que dela se extrai (ou não). É sobre algumas dessas concepções que este artigo se debruça, particularmente, a partir de um elemento específico - o ouro - e de uma dada região - a Amazônia brasileira.

Para tanto, este artigo lança luz sobre diferentes perspectivas - indígenas e não indígenas - acerca do ouro e sua garimpagem em partes da Amazônia brasileira. Trata-se, em grande medida, de um ensaio bibliográfico que traz dados etnográficos acerca das relações que os Yanomami, os Waiãpi, alguns povos indígenas do Alto Rio Negro e garimpeiros não indígenas estabelecem com os garimpos de ouro a partir dos anos 1970 na Amazônia. A análise comparativa entre processos históricos e etnográficos específicos permitiu revelar uma miríade de modos de se construir relações entre humanos, não humanos e garimpo. Relações que, por sua vez, impactam as decisões políticas que diferentes coletivos (indígenas e não indígenas) tomam frente ao ouro, ao garimpo e à mineração de forma mais ampla.

A urgência deste debate se deve ao aumento do número de desastres - ambientais e sociais - decorrentes de atividades minerárias ${ }^{5}$ (o mais recente sendo o rompimento da Barragem Córrego do Feijão, da Empresa Vale, no município de Brumadinho - MG, em janeiro de 2019), à grandeza dos números de processos minerários requisitados junto ao Departamento Nacional de Produção Mineral (DNPM) incidentes em Terras Indígenas ${ }^{6}$, e também à força que discursos e práticas a favor da flexibilização da exploração minerária em Terra Indígena vem adquirindo em diversas instâncias do governo e de órgãos legisladores do Brasil. Além da urgência política do debate, trazer à luz diferentes perspectivas locais indígenas e não indígenas - acerca do ouro, atividades minerárias, suas possibili-
1 Este artigo é fruto de algumas reflexões decorrentes de minha pesquisa de pós-doutorado, desenvolvida no Instituto de Filosofia e Ciências Humanas da Unicamp, dedicada à etnografia das atividades e discursos implicados na Política Nacional de Gestão Ambiental e Territorial em Terras Indígenas no Alto Rio Negro. Agradeço à Fundação de Amparo à Pesquisa do Estado de São Paulo (Fapesp), pelo apoio financeiro à pesquisa (Processo n²016/03589-3). Agradeço imensamente a leitura atenta feitas pelos colegas Felipe Vander Velden, Antonio Guerreiro Junior, Dayana Zdebsky de Cordova e Piero Leirner de versões preliminares do texto; bem como aos pareceristas anônimos do Anuário Antropológico, que também muito contribuíram para a versão apresentada aqui.

2 Dentre essas ciências, cito a geologia, a mineralogia, a gemologia, a engenharia de minas, para ficar em apenas alguns exemplos.

3 Para transformações modernas decorrentes da exploração e manufatura de metais, ver Goody (2012); para uma história do ouro, ver Bernstein (2000) e Hart (2013); para uma análise das relações entre ouro e prata na conquista das Américas, ver TePaske (2010).

4 Para uma análise da relação entre produção de mercadorias e seus criadores, os quais acabam sendo governados por suas criações - as próprias mercadorias -, ver Taussig (2010).

5 Muitas são as diferenças entre garimpo e mineração. Enquanto a mineração é controlada por empresas, o garimpo é controlado por um "chefe" ou "dono do garimpo". As empresas mineradoras geralmente atuam em regiões onde pesquisas geológicas indicam a existência de minérios, os quais, muitas vezes, estão em regiões montanhosas ou em porções mais profundas do solo, o que faz com que sua extração dependa de equipamentos e tecnologias avançadas, além de um alto número de funcionários e técnicos. Já nos garimpos, a 
dades, potencialidades e perigos, poderá contribuir para o debate antropológico e etnográfico feito pela "antropologia da mineração".

Primeiramente, apresenta-se o material publicado acerca das experiências e considerações Yanomami e Waiãpi a respeito do ouro e da garimpagem, a partir dos trabalhos de Bruce Albert e Davi Kopenawa (Albert, 1995; Kopenawa; Albert, 2015), e Dominique Tilkin Gallois (1985, 1989, 1991, 1993). Acrescentam-se a isso dados referentes à região do Alto Rio Negro, mais especificamente, algo das perspectivas Tukano $^{8}$ e Baniwa ${ }^{9}$ acerca do ouro (e também de outros minérios) e sobre as possibilidades de garimpo e mineração em seus territórios. Em seguida, busca-se relacionar aspectos destes pensamentos indígenas a respeito dos minérios às narrativas e contos de garimpeiros da Amazônia brasileira coletados pela pesquisadora Candace Slater (1994) na década de 1990. Por fim, esboça-se uma reflexão sobre as distâncias e medidas de segurança ou insegurança trazidas por essas diferentes perspectivas em relação ao ouro.

\section{A busca pelo ouro: entre fascínio e enigma}

Os povos originários da Amazônia, conhecedores exímios de seus territórios, há muito sabem da existência de ouro por lá. Foi, dentre outras coisas, em busca de ouro e metais preciosos que exploradores europeus navegaram mares afora, e estabeleceram colônias nos novos continentes descobertos e espoliados. De modo mais específico em relação ao ouro e ao Brasil, o primeiro documento que faz referência à produção de ouro no Brasil, segundo Calógeras (1904), data de $1681^{10}$. Em 1731, o Brasil já era o maior produtor mundial de ouro, com a marca de 12,7 toneladas (Noya Pinto apud Figueiredo, 2018) ${ }^{11}$. Embora já se soubesse da existência de ouro na Amazônia desde 1747, quando bandeirantes descobriram ouro na região do rio Tapajós, no Pará12 ${ }^{12}$ a produção brasileira de ouro no período dos setecentos estava baseada na exploração do território que hoje constitui o estado de Minas Gerais. A chamada "corrida do ouro" na Amazônia se deu mesmo após a década de 1970, em decorrência, principalmente, da crise do petróleo. ${ }^{13}$

A corrida pelo ouro nessa região na década de 1980 teve como resultado o aporte de 487 toneladas de ouro à economia brasileira, o equivalente a $60 \%$ da produção nacional deste metal (Ministério de Minas e Energia, 1993). Mas, estima-se que a maior parte da produção tenha sido vendida ilegalmente; ou seja, não se conhecem os números reais da produção e comercialização aurífera ${ }^{14}$. Quanto ao mercado internacional do ouro, tenhamos em mente que, entre 1943 e 1973, a taxa da onça (28,34 gramas) de ouro na bolsa de Londres oscilava entre 35 e 42 dólares, ao passo que em 1979 a taxa atingiu o recorde histórico de 850 dólares ${ }^{15}$. Isso certamente alavancou a garimpagem ao status de atividade econômica dominante na Amazônia. ${ }^{16}$ Albert informa que em 1987 havia cerca de meio milhão de garimpeiros produzindo 120 toneladas de ouro na região.

Segundo Bruce Albert (1995), a ocupação da Amazônia brasileira se deu em ciclos baseados na exportação de produtos extrativos e exploração da mão de obra indígena. Esses ciclos foram: no século XVII, o das chamadas "drogas do sertão"; do cacau, no século XVIII, e da borracha, no século XIX. Após um período de es- extração é feita individualmente ou por pequenos grupos e/ou cooperativas de garimpeiros, manualmente ou com maquinário bastante rudimentar, em geral, de propriedade do "dono do garimpo". Outras características do garimpo são a imprecisão na extração, devido à ausência de planejamento de mina e estudos geológicos mais precisos; a baixa tecnologia e/ ou métodos de extração pouco sofisticados; pouca estrutura operacional e empresarial na e da mina; pouca ou nenhuma preocupação com cumprimento de leis, com a segurança dos trabalhadores, e com os impactos sociais e ambientais da atividade; elos com redes não convencionais ou ilegais de crédito e compra de ouro; baixa transparência ou ausência dela no que se refere ao volume extraído e à venda do minério (Wanderley, 2015a, p. 1).

6 Segundo o Instituto Socioambiental (Rolla; Ricardo, 2013), até 2013 existiam 4.116 requerimentos para exploração de subsolo em 147 terras indígenas registrados na Agência Nacional de Mineração, envolvendo cerca de 90 tipos de substâncias, sendo que quase a metade tem o ouro como objeto (também aparecem cobre, cassiterita, tântalo, titânio, bauxita, dentre outras). Para se ter uma ideia, as TIs Cajueiro (RR), Arara (PA), Baú (PA), Kwazá do Rio São Pedro (RO), Pequizal (MT), Roosevelt (RO) e Xikrin do Cateté (PA) têm mais de $90 \%$ de seus territórios com incidência de processos de interesse mineral. Outras 35 TIs têm mais de 50\% de sua extensão em situação semeIhante. As Terras Indígenas com mais processos são a Yanomami (AM/RR) com 640 processos; a Mekragnoti (PA), com 413, e a Alto Rio Negro (AM), com 364 processos. Mais dados sobre a pressão das atividades minerárias sobre terras indígenas, ver Carneiro Filho e Braga de Souza (2009).

7 Desde 1985, com a publicação do seminal artigo de Ricardo Godoy (1985), no qual se apontava a necessidade de consolidação de um campo que 
tagnação seguiu-se o advento dos planos de integração geopolítica dos governos militares dos anos 1960 e 1970. Durante os governos militares, a abertura de malha viária, a construção de hidrelétricas, a criação de programas de colonização e a atração de investimentos nos setores mineral, agropecuário e florestal promoveram a rearticulação da fronteira amazônica ao "sistema mundial", segundo o autor, "por uma política em grande escala de ocupação demográfica, de desenvolvimento econômico e de redistribuição espacial promovida pelo Estado" (Albert, 1995, p. 2). Em reação a essas múltiplas estratégias antagônicas de territorialização ${ }^{17}$ promovidas pelos governos militares surgiram movimentos também múltiplos de resistência, nos quais a luta pela reivindicação de reservas de terra enquanto "contra-espaços" diferenciados no interior da fronteira e, principalmente, da floresta - terras indígenas, reservas extrativistas etc. - foi a principal bandeira. Embora não seja este o foco do presente artigo, não se pode ignorar a centralidade do movimento indígena e das lutas pela demarcação na configuração da Amazônia a partir da década de 1970 .

\section{O ouro sob perspectivas xamânicas}

Em artigo intitulado "O ouro canibal e a queda do céu: uma crítica xamânica da economia política da natureza" (1995), Albert traz à luz, dentre outras coisas, pontos importantes para se entender, a partir da perspectiva Yanomami, a relação que este povo tem com os minérios e também com o território (seja este a territorialidade, tal como vivida e praticada pelos índios, seja a categoria genérica de "terra indígena", herdada do código jurídico da sociedade envolvente, que foi, conforme demonstra o autor, reorientada como condição política de resistência e permanência da especificidade social dos povos indígenas ${ }^{18}$. O material no qual o autor se baseia é o discurso de Davi Kopenawa, xamã cuja trajetória interétnica, associada ao universo das ONGs indigenistas e ambientalistas, tomou forma durante os anos 1980, justamente o período no qual as terras de seu povo Yanomami eram diuturnamente invadidas por uma atroz corrida do ouro. Davi Kopenawa ofereceu a Bruce Albert uma importante "crítica ao fetichismo do ouro".

Em 1989, havia no território Yanomami em Roraima entre 30 e 40 mil garimpeiros, 150 garimpos e 82 pistas de pouso. A estes garimpeiros os Yanomami chamavam "urihi wapope", termo traduzido por Albert e Kopenawa como "comedores de terra, comedores de floresta". A atividade garimpeira espalhou violência e doenças, que resultaram em milhares de mortes, poluição de rios, diminuição da caça e desmatamento. Foi contra os "comedores de terra" que lideranças Yanomami, como Davi Kopenawa, construíram um discurso que reivindicava o direito a manter o uso exclusivo de seu território tradicional, um discurso apoiado na expressão "urihi noamãi", que trata do "recusar-se (a entregar)" e "proteger" a "terra, a floresta".

Albert mostra em seu artigo como a avidez dos garimpeiros pelo ouro, a despeito da sujeira na qual essa atividade implica e as febres mortais que ela espalha, era um "trágico enigma" para os Yanomami (ibid., p. 10) ${ }^{19}$. Parte da resposta a este enigma, segundo Davi Kopenawa, é resultado da "ignorância dos brancos" e da se poderia chamar "antropologia da mineração" e, posteriormente, com a atualização desse artigo feita por Chris Ballard e Gleen Banks (2003), enfatiza-se a importância de ultrapassar uma perspectiva binária entre estados e empresas sobre benefícios e impactos da mineração, incorporando as representações de comunidades locais (ver também Zhouri, 2017), potencialmente enriquecendo o campo de pesquisas sobre garimpos na Amazônia, que abordam temas como: prospecção (Lestra; Nardi, 1994); impactos sociais, como doenças, por exemplo (Amoras, 1991); impactos ambientais (Silva, 1988); prostituição e trabalho da mulher (Dimenstein, 1992); significado econômico da mineração (MacMillan, 1993; Pereira, 1991; da Silva, 1994); políticas públicas minerais (Cascaes; Oliveira, 1993); técnicas alternativas para a garimpagem do ouro (Dourojeanni; Pádua, 2013); violência (Zhouri, 2018); e efeitos nas culturas indígenas (Burkhalter, 1982).

8 Refiro-me aqui tanto à multiplicidade de povos falantes de línguas do tronco Tukano Oriental, que engloba pelo menos 16 línguas, dentre as quais o Tukano propriamente dito é a que possui o maior número de falantes (Disponível em: https://pib.socioambiental. org/pt/Povo:Tukano. Último acesso em: 25 fev. 2019).

9 Povos falantes de uma língua da família linguística Aruak, habitantes das bacias dos rios Içana e seus afluentes Cuairi, Aiari e Cubate, na região do Alto Rio Negro. Wright (2005, p. 19) lembra que Baniwa não é uma autodenominação tradicional, mas um termo utilizado desde tempos coloniais para se referir ao conjunto de povos de língua Aruak habitantes do Alto Rio Negro. Entre eles, utiliza-se a distinção pelos nomes de suas fratrias

10 Apesar de ser este o primeiro documento oficial que faz referência ao ouro no território colonial que hoje configura o Brasil, não se pode ignorar a circulação de lendas como a do 
“escuridão confusa” de seu pensamento "plantado nas mercadorias”. Suas palavras sobre os garimpeiros são as seguintes:

Os garimpeiros são hostis a nós porque são como espíritos maléficos; são filhos de comedores de terra-floresta. Eles dizem que nós somos ignorantes, mas estão errados. É o contrário. Somos nós que sabemos das coisas e que protegemos a floresta. Somos amigos da floresta porque nossos espíritos xamânicos são os seus guardiães (...) São eles que nos fazem pensar direito e ficar lúcidos. Quando estão perto de nós, fazem crescer nossa mente, fazem-na ir longe. Nosso pensamento não é fixado em outras palavras. É fixado na floresta, nos espíritos xamânicos (...) Os brancos não conhecem esses espíritos de fertilidade da floresta. Eles acham que ela só existe à toa, por isso a destroem. (ibid., p. 11).

Nessa perspectiva, xamânica, os Yanomami sabem que o ouro - "coisa escondida no interior da terra, embaixo da água dos rios" - é matéria quente e perigosa, um antialimento patogênico, que foi, justamente por causa dessas propriedades, escondido junto com outros minérios embaixo da terra por Omamë ${ }^{20}$. Eles afirmam que "enquanto for conservado no frio das profundezas da terra[,] o ouro é inofensivo" (ibid., p. 13). De outro lado, inescrupulosamente, os garimpeiros, além de extraírem este ouro das profundezas da terra, "ainda o queimam e o expõem ao sol em latas de metal. Este aquecimento 'mata' o ouro o e o faz 'exalar' uma fumaça pestilenta que se propaga em todas as direções" (ibid., p. 13). ${ }^{21}$ Segundo Albert e os Yanomami, este "calor patogênico" afeta tanto os seres humanos quanto a floresta, que vê seu "princípio de fertilidade" fugir, tornando-a inabitável para seus donos, os espíritos xamânicos que possuem e protegem a floresta.

A crítica cosmológica feita por Davi Kopenawa a uma atividade econômica, a garimpagem, o leva a relacionar os brancos ao "Xawari", o "espírito da epidemia", ser canibal que tem a aparência de um branco, que "mata e come nossos filhos", explica Kopenawa. Porém, o ciclo de destruição não se encerra aí. Segundo Davi Kopenawa, a "epidemia-fumaça" introduzida pela atividade garimpeira e os poderes patogênicos liberados pelos brancos resultam no extermínio dos próprios xamãs, que restam impotentes e aniquilados pela captura e fuga de seus espíritos auxiliares, quando da destruição da floresta. ${ }^{22}$ Bruce Albert argumenta, por fim, que "a corrida do ouro instaura (...) uma crise escatológica e um movimento de entropia cosmológica”, confirmando a profecia apocalíptica feita por Davi Kopenawa (Albert; Kopenawa, 2015), de que quando todos os xamãs tiverem morrido, o céu vai cair. Um bom resumo desta ideia está na seguinte passagem:

A corrida do ouro representa, pois, uma irrupção de forças destrutivas tão incontroláveis no interior da floresta e do universo que só podem ser associadas à memória mítica das transformações erráticas dos ancestrais animais (daí talvez, a denominação dos garimpeiros como "espíritos queixada" e das mineradoras como "espíritos tatu-canastra"). (Albert, 1995, p. 17).
Eldorado em toda a América (espanhola e portuguesa). Trata-se de uma lenda indígena conhecida no período das colonizações que narra a existência de uma cidade construída de ouro maciço.

11 Figueiredo (2018, p. 52) salienta que para o mesmo ano (1731), a produção da Europa e da África somadas não alcançava 10 toneladas de ouro. Em 1750, o Brasil atinge a marca de 15,5 toneladas anuais (Metamig, 1981; Coppola, 1994) Para dados e uma análise dos mesmos referente à região amazônica, ver Costa (1993). 12 Não apenas de ouro são feitas as reservas minerais da Amazônia. Nesta região encontram-se grandes reservas de minério de ferro, bauxita, manganês, cobre, níquel, cromo, cassiterita, zinco, zirconita, calcário, caulim (DNPM - Informativo mineral Regional Norte - Amazônia 2008/2007), bem como as chamadas terras raras (grupo constituído por 17 elementos usados principalmente em áreas de alta tecnologia, para os quais ainda não são conhecidos substitutos que proporcionem o mesmo desempenho) (Usos e aplicações de Terras Raras no Brasil: 2012-2030, 2013).

13 O desenvolvimento de garimpos no rio Tapajós começou, segundo Leroy e Malerba (2010), em 1958, tendo sido seu período de maior atividade as décadas de 1970 e 1980. Segundo esses autores, a garimpagem é atualmente praticada em todos os estados da Amazônia brasileira, com exceção do Acre, sendo que o sul do Pará é onde estão os garimpos de mais fácil acesso. Na Amazônia, há ocorrência de ouro, com maior frequência, em depósitos primários (veios) ou na forma de lascas e partículas minerais em depósitos secundários (sedimentos); nessas rochas, o ouro associou-se com sílica líquida ao longo de episódios de formação e consolidação de magmas. Subsequentemente, a erosão de algumas dessas rochas ricas em ouro formou os depósitos 
Outras perspectivas indígenas sobre o ouro nos são apresentadas pelos Waiãpi, através dos trabalhos de Dominique Gallois. Falantes de língua Tupi e habitantes da região delimitada pelos rios Oiapoque, Jari e Araguari, no Amapá, os Waiãpi acumulam experiências de confronto com garimpeiros invasores desde o início da década de 1970 (Gallois, 1993). Os garimpeiros chegaram ao território Waiãpi antes mesmo da frente de atração da Funai que acompanhou a construção da rodovia Perimetral Norte, em 1973 (ibid.). Ou seja, as invasões garimpeiras foram também cruciais na luta pela demarcação da Terra Indígena e nas atividades de controle territorial. No artigo "O discurso Waiãpi sobre o ouro - um profetismo moderno", de 1989, Gallois apresenta algumas dessas considerações waiãpi a respeito desse minério encontrado na bacia dos rios Aimã/Inipuku.

Assim como relatado por Davi Kopenawa, os Waiãpi entendem que a invasão garimpeira em suas terras provoca um "apodrecimento acelerado da terra", e o que se observa em termos materiais - as derrubadas, a poluição e a lama dos garimpos - esconde uma realidade cosmológica, à qual a autora dá maior atenção. Mas, não apenas isso, o fato de terem vivido uma experiência de contato com garimpeiros no sul da área, que provocou a morte de cerca de 40 pessoas em decorrência de uma epidemia de sarampo, colocou o garimpeiro como figura central na ideologia e nas práticas de enfrentamentos entre os Waiãpi e os brancos (Gallois, 1989) ${ }^{23}$.

Em 1983, o líder da comunidade de Mairy tomou para si as ferramentas de garimpeiros invasores e, desde então, tem acesso ao ouro e ao dinheiro, em uma ação apoiada sobre mitos e que objetivava nortear o destino de seu povo, num futuro que dependia, conforme aponta Gallois (ibid.), do controle Waiãpi sobre seu território e de um uso parcimonioso do ouro. E por que o ouro deve ser usado de maneira comedida? Em um discurso, este líder, Waiwai, remete a uma série de elementos da cosmologia e cataclismologia Waiãpi, tais como: terra/água/fogo e pedra/lama. Os três primeiros elementos remetem ao mito de destruição do mundo, pelo fogo e pelo dilúvio. Gallois explica que:

"secar" os igarapés com a abertura de buracos e o desvio das águas, nos garimpos, representa para os Waiãpi, um sinal de cataclismo. A “seca”, a rarefação de águas, antecede - em todos os relatos tradicionais - a chegada do "grande fogo" que destruiu a primeira humanidade. Na recriação do Universo, lanejar garantiu perenidade a esta terra, colocando nela o ouro, que segundo os Waiãpi, "segura” as águas, ao mesmo tempo que confere à terra uma juventude eterna (ibid., p. 465).

A plataforma celeste, na qual mora o herói criador, também é construída sobre uma laje de pedra, fato que leva os Waiãpi a associarem simbolicamente pedra e imortalidade. Já a lama, num polo oposto, "representa a 'podridão' da terra, relacionada com a mortalidade da atual humanidade. $O$ podre é normalmente associado ao número elevado de sombras de mortos que se misturam à terra" (ibid., p. 465). Ou seja, deve-se considerar que, na escatologia Waiãpi, "a presença de lama é um sinal de cataclismo", pois se refere à "presença excessiva de sombras secundários (MME, 1993). Nesta região costuma-se empregar duas técnicas para extração de ouro: na de exploração aquática um mergulhador utiliza uma motobomba para succionar os sedimentos mineralizados no fundo de um rio e transferi-los para uma caixa concentradora fixada em uma balsa; neste processo de concentração na caixa, adiciona-se mercúrio para reduzir as perdas de ouro, pois ouro e mercúrio formam uma amálgama, a qual, posteriormente, é queimada para separar os dois elementos; no método mais comum, entretanto, utilizam-se duas motobombas, uma que lança água sob pressão nos sedimentos e outra que bombeia o sedimento e a água até uma caixa concentradora: esta é a técnica terrestre utilizada nos aluviões.

14 Imazon. Disponível em: http://imazon.org.br/impactos-da-garimpagem-de-ouro-na- amazon-n-2/?lang =en. Último acesso em: $1^{\circ}$ fev. 2019

15 Dados disponíveis no site do World Gold Council (https:// www.gold.org/. Último acesso em: 25 fev. 2019). Sobre a geopolítica e a geoeconomia mundial do ouro, ver Wanderley (2015a, 2015b).

16 Para análises sobre a garimpagem na Amazônia ver Cleary $(1990,2000)$.

17 De acordo com Albert (1995), o Estado impulsionou a ocupação do território amazônico tanto por parte dos militares, quanto de empresas públicas e privada (como mineradoras, florestais, hidrelétricas, agropecuárias), bem como por parte de pequenos agricultores, garimpeiros, seringueiros, índios etc. É neste sentido que o autor faz referência a estratégias antagônicas de ocupação, pois nem sempre as experiências de/ no território vividas e desejadas por estes grupos e agentes diversos coincidem ou podem conviver harmoniosamente. Outro autor que enfatiza a importância dos recursos minerais da Amazônia nos projetos de ocupação deste território é Dos Santos (2002).

18 Sobre a categoria "terra 
'podres' na terra e, paralelamente, ao peso excedente dos mortos no céu” (ibid., p. 466). O discurso de Waiwai alerta para o perigo representado pela presença de garimpeiros invasores, que extraem o ouro e outros minérios desmedidamente, sem cuidados e limites, porém, não exclui todas as possibilidades de extração do ouro da terra. O conhecimento cosmológico e xamânico Waiãpi e a irresponsabilidade dos brancos fornecem os fundamentos para que Waiwai conceba apenas a possibilidade de trabalho exclusivamente indígena no garimpo.

\section{Garimpagem Waiãpi de ouro: entre xamanismo e política}

O início da relação entre os Waiãpi e os garimpeiros foi bastante violento, culminando, em 1982/83, na expulsão destes e na eliminação dos principais focos de invasão na área indígena. Nesse movimento, os Waiãpi aprenderam a trabalhar na extração manual do ouro e passaram a ver nesta atividade uma possibilidade de obter os recursos necessários para adquirir bens que eram, até então, distribuídos pela Funai como "presentes” no contexto de “atração” de povos isolados (Gallois, 1993). Assim, eles chegaram à formulação de que a garimpagem é uma atividade que deve ser exclusivamente controlada pelos próprios Waiãpi e, segundo o Cacique Waiwai, "o ouro é nosso, nós vamos trabalhar sozinhos, devagar, porque o ouro não estraga, está guardado em nossa terra” (ibid.). Garimpar para os Waiãpi não constitui, portanto, uma contradição ao fato de que é o ouro quem confere perenidade à terra porque, nas tradições míticas deste povo, são eles os responsáveis pela preservação da terra criada por seus heróis míticos, que lhes destinaram, inclusive, o ouro.

De certo modo, a garimpagem de ouro feita pelos Waiãpi foi, por eles mesmos, avaliada como bem-sucedida. Resta saber por quê. Primeiro porque andou em paralelo com as atividades de controle e ocupação territorial. A ocupação das fronteiras norte e sul da área Waiãpi e o processo de dispersão de aldeias, após um período de concentração populacional em torno dos postos de assistência da Funai e das missões evangélicas, têm muito a ver com a necessidade de controlar zonas que vinham sendo intermitentemente invadidas por garimpeiros; fiscalização das invasões e pesquisa de ouro se tornaram, inclusive, duas faces da mesma estratégia de controle territorial, segundo Gallois (ibid.).

No início dos anos 1990, Gallois estimou que 1/3 da população Waiãpi estava envolvida na garimpagem manual de ouro. Cada grupo familiar (composto por 4 ou 5 pessoas de diferentes gerações) passava duas temporadas de trinta dias no garimpo por ano, obtendo, em cada temporada, cerca de 10 gramas de ouro. $\mathrm{O}$ trabalho no garimpo Waiãpi era mais uma atividade familiar que coletiva, que envolveria todos os membros de uma “aldeia”. Mas, além disso:

a garimpagem integra-se harmoniosamente ao ritmo do ciclo sazonal de atividades de subsistência; enfatiza a divisão dos segmentos residenciais que mantêm sua autonomia na exploração de grotas específicas; a produção apoia-se nas normas tradicionais de divisão do trabalho (...); a distribuição dos lucros acompanha as divisões tradicionais que se perpetuam através das ‘equipes' no garimpo etc.” (ibid.: s/p) ${ }^{24}$. indígena", ver também "EntreTerras" (2017); Barreto Filho (2002); Miras (2017); Sáez (2015); Cavalcante (2016), dentre outros.

19 A correlação entre febre e ouro recebe especial atenção do pesquisador André Guedes (2015), para quem a "febre do ouro" seria um estado simultaneamente social e corporal que se localiza entre a paixão e a doença. A partir de pesquisa realizada no município de Minaçu (onde são realizadas atividades garimpeiras e minerárias desde a década de 1950), ao norte de Goiás, Guedes escreve que a agitação e o frenesi após o anúncio da descoberta de ouro tomaram conta da cidade e das pessoas: "cidade febril, corpos e corações febris, espíritos exaltados e perturbados... A febre, num caso como no outro, remete a um movimento que não é apenas súbito e temporário, mas marcado por intensidades bastante particulares, em que o processo mais amplo que contagia e movimento as localidades reproduz-se nas pessoas, corpos e vidas que foram por ele arrastados" (Guedes, 2015, p. 123).

20 Na mitologia Yanomami, Omamë é o demiurgo criador do mundo atual e da humanidade (Albert; Kopenawa, 2015).

21 Vale lembrar ainda que os Yanomami já haviam percebido essa "fumaça do metal" nos terçados e instrumentos de ferro e aço, conhecimento antes mesmo da chegada dos garimpeiros aos seus territórios (Albert; Kopenawa, 2015). 22 A estimativa é de que para cada $1 \mathrm{~kg}$ de ouro produzido, 1,3 kg de mercúrio é emitido no ambiente (Dourojeanni; Pádua, 2013). Outro trabalho estima que mais de 30 toneladas de mercúrio sejam despejados anualmente nos rios da Amazônia (considerando os nove países dessa região) (https:// globalinitiative.net/organized-crime-and-illegally-mined-gold-in-latin-america/. Último acesso em: $1^{\circ}$ fev. 2019).

23 A autora explica o modo 
Mais do que se integrar ao ritmo de vida Waiãpi, Gallois argumenta que as expedições de pesquisa e extração de ouro também representavam a oportunidade de inspecionar fruteiras e trilhas de caça e de revisitar locais onde eram rememorados eventos históricos e culturais importantes para a perpetuação da memória do grupo. A ocupação intermitente das zonas de garimpo levou, portanto, à recuperação e ao enriquecimento florestal e da biodiversidade, de um lado, e das memórias do grupo, de outro.

\section{Noroeste Amazônico: indígenas, garimpeiros e mineradoras}

Outro território indígena no qual é conhecida a presença de diversos minérios é a região do Alto Rio Negro. Por lá, também desde a década de 1970, os mais de 20 povos indígenas convivem (entre confrontos e negociações) com garimpeiros, empresas mineradoras, atividades minerárias e os minérios propriamente ditos. O primeiro garimpo explorado na região ficava na Serra dos Porcos (Apidzattoroni, em baniwa), que já em 1970 teve ouro explorado, por indígenas e não indígenas. Em seguida, foram abertos garimpos na Serra do Caparo (Pewá, também em território Baniwa) e na Serra do Traíra, em território de ocupação Tukano e Yuhup. Em todos esses garimpos houve a presença e o trabalho de indígenas, garimpeiros não indígenas e de empresas mineradoras.

Foi em algumas viagens aos garimpos da Serra dos Porcos e da Serra do Caparro que alguns índios tukano de comunidades espalhadas pelo rio Tiquié começaram a se interessar em procurar minérios também em seus territórios. Em entrevista ao antropólogo Carlos Alberto Ricardo, no ano de 1987, uma liderança indígena tukano disse ter ido com alguns de seus irmãos "trabalhar na cabeceira do Içana em 1982" e ter voltado com "amostras de ouro"25. A partir daquela amostra, este grupo voltou a Pari-Cachoeira e começou a pesquisar e a prospectar, encontrando ouro em 1984 na Serra do Traíra. Berta Ribeiro escreve, em relatório para o Conselho Indigenista Missionário (CIMI), que "em dezembro de 1985 havia cerca de 400 índios na Serra do Traíra" (1987, p. 11)26. Desde o início de sua operação, o garimpo da Serra do Traíra foi organizado e administrado pelos dirigentes da União das Comunidades Indígenas do Rio Tiquié (UCIRT) ${ }^{27}$. Atividade que envolvia desde a organização do acesso de indígenas aos locais de trabalho, a segurança na região, a comercialização e o transporte dos produtos extraídos, até as tentativas de negociação e diálogo com empresas mineradoras e órgãos estatais.

Na região do rio Içana, a exploração do ouro levou ao conhecimento da existência de outros minérios, tais como a tantalita ${ }^{28}$. Um regatão ${ }^{29}$ que percorria a região foi quem introduziu um grupo de garimpeiros em um igarapé próximo à comunidade de Tamanduá (no rio Içana). Foi ele também quem inicialmente comercializou a tantalita extraída no Içana (Andrello, comunicação pessoal). Assim, apesar do desconhecimento em relação à finalidade e aos usos deste minério, muitas comunidades colecionavam algumas amostras. No final de 1995, um conjunto de comunidades baniwa do médio Içana decidiu montar um sistema autônomo de exploração, escoamento e comercialização de tantalita e de mercadorias nos garimpos. A articulação foi feita pela Organização Indígena da Bacia do Içana como os "carai-ko", os brancos, são classificados socialmente pelos Waiãpi ocupando uma posição ambígua, "às vezes integrados ao sistema mas em outros momentos excluídos" (ibid., p. 458). Se, por um lado, na classificação etiológica de seus inimigos feita pelos Waiãpi os brancos quase nunca aparecem, na classificação histórica eles são situados na "periferia do Universo", uma posição que "partilham com uma categoria específica de inimigos: os apã-wer, inimigos 'antigos' (isto é, eliminados: wapsipa)” (ibid., p. 459). Some-se a essas classificações, a mitológica, na qual os Waiãpi registram a diferença entre uma humanidade propriamente "criada" pelo herói lanejar [herói criador Waiãpi deste mundo no qual vivemos e agimos atualmente] e uma outra humanidade "residual", da qual fazem parte os brancos. Segundo Gallois, "esta classificação mostra que os brancos são totalmente diversos, e isto está posto desde o tempo das origens, uma vez que não surgiram da mesma forma que a 'verdadeira humanidade”' (ibid., p. 459). 24 Através do programa de assessoria desenvolvido entre os Waiãpi e o CTI chegou-se a três medidas básicas, que foram rapidamente implementadas: a eliminação total do uso do mercúrio para limpeza do ouro; "a inclusão de um pequeno conjunto de motobomba para esgotar as escavações e fornecer água para a caixa concentradora durante a limpeza do cascalho"; "a padronização da caixa concentradora com uso de material leve, de fácil transporte e manuseio, que permita regulagens de acordo com algumas variações das características físicas do minério" (ibid.).

25 Entrevista disponível em: https://acervo.socioambiental. org/acervo/documentos/ entrevista-do-sr-henrique-castro-tucano-tuxaua-de-pari-cachoeira-carlos. Acesso em: 25 fev. 2019.

26 É importante salientar que, nesta época, final dos anos 1980, não havia terra indígena 
$(\mathrm{OIBI})^{30}$, e envolveu a Federação das Organizações Indígenas do Rio Negro (Foirn), o Instituto Socioambiental (ISA) e duas empresas de mineração (Zangarelhas Mineração e Mineração Fluminense) ${ }^{31}$.

Segundo um dos integrantes deste projeto, os garimpeiros brancos acabaram saindo da região porque os indígenas estavam conseguindo praticar um valor melhor na venda do minério explorado, além de conseguirem levar mercadorias a um preço mais baixo para os garimpos nos quais os indígenas estavam trabalhando. Esse projeto durou dois anos: alguns comerciantes, indignados porque tinham perdido o monopólio da comercialização, denunciavam os indígenas, como se estes estivessem garimpando clandestinament ${ }^{32}$, mas, estes sempre o fizeram com parcimônia e respeito aos "donos" dos minérios. Posteriormente, os baniwa remanejaram os recursos deste projeto para o Arte Baniwa $a^{33}$, que trabalhou com cestarias.

Um antigo capitão ${ }^{34}$ da comunidade de Castelo Branco (no rio Içana) disse, certa vez, a Andrello (comunicação pessoal), que todos os minérios possuem uma força específica, chamada em Baniwa liwawaronaa, um poder que vem diretamente de sua sombra (ou alma, ou espírito), chamada linaaphia (em baniwa). Os donos desses minérios são Yoopinai (em baniwa; seres invisíveis, animais no mundo diante dos nossos olhos, que no seu lugar são gente como nós ${ }^{35}$. Eles são os protetores destes minérios, que são enfeites e fazem parte dos jardins de suas cidades (iarodattinai, em baniwa). São com eles que fazem também suas joias e adornos. Aquele capitão dizia que, por possuírem alma, os minérios também estão vivos, e por isso devem ser mantidos na água, como os peixes, para que não morram. Seus donos, ou pais, se aborrecem quando os homens passam a retirar minério em excesso e então exigem alguma retribuição. As mortes que ocorrem em demasia nos garimpos se devem a isso; ou seja, não são as brigas ou desentendimentos entre os homens que provocam mortes, mas o pai do minério leva alguns garimpeiros em troca do minério extraído ${ }^{36}$. Recentemente, um interlocutor baniwa acrescentou a essa explicação que os desastres ecológicos também acontecem pelos mesmos motivos. Ou seja, há um limite conhecido pelos indígenas, mas não pelos brancos, para a exploração.

Na região do Alto Rio Negro, o ouro aparece também nas narrativas acerca de Ermanno Stradelli ${ }^{37}$. Os tariano ${ }^{38}$ Manuel Marcos Barbosa e Adriano Manuel Garcia (Barbosa; Garcia, 2000) contam que Stradelli foi o primeiro branco a chegar na "maloca dos Tariana" (por volta do ano de 1883) e que ele era como um antropólogo, porque ia de maloca em maloca, no Uaupés, fazendo sempre as mesmas perguntas sobre clãs, cantos e danças tradicionais. A parte que nos interessa nessas narrativas são suas idas a três serras em busca de ouro, quando, durante suas viagens, seu dinheiro acabava. Na narrativa consta que ele foi até a Serra da Noite (Lepi-panisi, em tariano), a Serra dos Vestidos (Paramali-taki) e a Serra de Bogotá (Hema-yapirikuli-panisi), todas elas guardadas por seres específicos designados em tariano como Lepi-iñe ${ }^{39}$. Da primeira serra, nas proximidades da Cachoeira de Itapinima, no rio Cuduyari, o conde Stradelli obteve ouro em troca de alguns objetos pessoais, como cadeiras. Na segunda serra, ele não obteve sucesso, somente foi abraçado pelo "guardião" (Lepi-iñe), tendo saído de lá com o corpo todo melado demarcada na região, o que havia, desde 1979, era o reconhecimento da Área Indígena de Pari-Cachoeira. Ou seja, a preocupação indígena em "ocupar" o garimpo, diante das invasões de garimpeiros brancos que já começavam a ocorrer, era mais do que legítima na defesa territorial, assim como nos casos Yanomami e Waiãpi.

27 A União da Comunidade Indígena do Rio Tiquié foi a segunda associação indígena oficializada na região do Alto Rio Negro, ainda em 1984, e a primeira a receber verbas para seu funcionamento e para o andamento de projetos. Mais informações sobre política indígena na bacia do Uaupés, ver Andrello (2004, 2008) e sobre o movimento indígena na região do Alto Rio Negro como um todo, ver Garnelo (2002); Peres (2003); Wright (2005); Luciano (2006); Soares (2012) e lubel (2015).

28 O Tântalo é um metal de transição, considerado raro, resistente à corrosão, que tende a ser encontrado junto ao Nióbio. Seu principal uso é a indústria de componentes eletrônicos. Em 2006, estimava-se que $47 \%$ do tântalo mundial estivesse em território brasileiro. Dados daquele ano colocavam o Brasil como o segundo maior produtor mundial deste metal, com 17\% da produção, atrás da Austrália (57,8\%) (DNPM/8Ds e Mineral Commodity Summaries-January/2007. Disponível em: http://www.anm.gov.br/ dnpm/ publicacoes/serie-estatisticas-e-economia-mineral/sumario-mineral/sumario-mineral-brasileiro-2007/tantalita_sm2007. pdf/view. Acesso em: 25 fev. 2019).

29 Comerciantes que usam barco para percorrer uma determinada região.

30 A Organização Indígena da Bacia do Içana - segunda associação da bacia do Içana foi criada em 1992. Atualmente congrega 10 associações, espalhadas por 93 comunidades. 31 Uma importante fonte de informações sobre as tensões internas geradas pelo garimpo 
de lodo. Os narradores não detalham o sucesso ou não da empreitada do conde na terceira serra. O que eles contam, porém, é que Stradelli fez essa mesma viagem três vezes e, da quarta vez, não mais voltou. Segundo os narradores,

os velhos dizem que ele provavelmente morreu. Eles costumam contar, com efeito, que quando alguém mexe em algum produto da natureza, tais como ouro ou diamante, por exemplo, o espírito desses minerais pede em troca o corpo e a alma de uma pessoa, seja da própria pessoa que mexeu com essas coisas ou de alguém de sua família. Como ele tinha avisado que faria uma quarta viagem na região mas nunca mais voltou, os velhos acreditam que o espírito do ouro pegou em troca a vida dele (Barbosa; Garcia, 2000, p. 258$)^{40}$.

Segundo Andrello (2004), os feitos de Stradelli, mencionados por várias pessoas na região do Uaupés, incluíam retirar dinheiro de caixas de pedra existentes em serras ou sob as pedras das cachoeiras, e extrair ouro amolecido que escoava também por algumas cachoeiras. Mas, nunca se deixa de mencionar que esses "tesouros escondidos" - dinheiro e ouro - tinham "guardiães" ou "donos".

\section{Perspectivas não indígenas: garimpeiros na Amazônia e suas narrativas}

Histórias de "tesouros escondidos" reaparecem também em muitos contos de brancos que garimparam e garimpam ouro na Amazônia"1. Além de "tesouros”, a morte é outro elemento constante nessas histórias e narrativas. Candace Slater é quem, partindo de dados coletados entre 1988 e 1992 em relatos gravados com mais de cem garimpeiros em diferentes regiões da Amazônia Brasileira, nos fornece tanto uma interessante imagem de como são (ou eram) os garimpos de ouro na Amazônia quanto algumas características do que a autora chama "contos contemporâneos de garimpeiros da Amazônia"42.

Conforme sugere Slater, as narrativas de tesouros escondidos são bastante difundidas pela Amazônia (assim como em outras localidades do Brasil). Geralmente esses contos partem da ligação entre tesouros de pessoas já falecidas e localidades específicas. As almas dessas pessoas que em vida acumularam riquezas costumam aparecer em sonhos para alguns indivíduos a fim de fornecer informações sobre a localização desses tesouros. Slater sintetiza que o que há de semelhante nessas histórias é o argumento do ouro como presente para um indivíduo em particular e não uma descoberta casual; a necessidade de sigilo na sua extração e as insinuações de má sorte em torno da posse do material.

De outro lado, o contrário ocorre nas histórias em que o ouro conscientemente se entrega a um homem que ele seleciona sob condições de sua própria escolha. Assim, nas narrativas feitas pelos garimpeiros, o que autora encontra são muitas referências a possíveis explicações para o sucesso ou fracasso das empreitadas. A fala de um garimpeiro gravada pela pesquisadora é bastante ilustrativa quanto a isso: "o ouro decide, e só ele sabe quando, e mesmo se, aparecerá”, o que não tem necessariamente a ver com atributos pessoais do garimpeiro. Nessas histórias, entre os Baniwa é Wright (1989), que mostra tanto que o enfrentamento baniwa às empresas mineradoras pode ser caracterizado como um episódio de tipo guerreiro - envolvendo ataque físico ao maquinário de prospecção das empresas e medidas de retaliação do exército brasileiro que incidiram sobre as lideranças indígenas

- quanto que as estratégias das companhias para assegurar o controle sobre as minas consistiu em dividir as lideranças Baniwa, o que efetivamente atrapalhou (ou tardou) a consolidação de suas comunidade na defesa de seus direitos.

32 Não obstante a regulação das atividades minerárias (garimpo e mineração) em terra indígena avance com lentidão nas instâncias legisladoras brasileiras, a legislação é clara em anunciar que a atividade garimpeira em terras indígenas é permitida apenas quando realizada pelos próprios povos indígenas, outros casos dependeriam de aprovação do Congresso Nacional. Para saber mais sobre os imbróglios legais referentes ao tema, ver: Villas Bôas (2005); Rolla; Ricardo (2013); Curi (2007); Souza Filho; Arbos (2011); e Valle; Batista; Pinheiro (2013).

33 Arte Baniwa é um projeto de comercialização de cestarias indígenas feitas por artesãos e artesãs baniwa em grandes lojas de São Paulo e outras cidades brasileiras. Trata-se também da criação da primeira marca indígena lançada nacionalmente (registrada no Instituto Nacional de Propriedade Intelectual). Este projeto já ganhou prêmios nacionais.

34 É o modo como se convencionou chamar os líderes comunitários da região do Alto Rio Negro.

35 Yóopinai é uma categoria genérica que encobre um coletivo (social) de seres que não são humanos em sua forma corporal (o que não quer dizer que não sejam humanos em sua condição essencial); "estão entre os espíritos mais importantes no cosmo Baniwa, seja por sua capacidade de 
é o comportamento aparentemente incompreensível do ouro que costuma ser o ponto salientado pelo narrador. Nelas, também é frequente a associação do ouro a uma entidade humana e, mais especificamente, feminina e dotada de agência.

Nos contos dos garimpeiros também são conferidas capacidades agentivas ao ouro após este ser encontrado, e não apenas no processo de sua busca (que mais se assemelha às características da caça e da sedução que às da coleta $)^{43}$. Conforme relatou um garimpeiro de 26 anos, "o ouro exige muita coisa da gente. Você não pode pensar em ganância - carro, casa boa, essas coisas - quando vai atrás dele. Pois se ligar para elas, zanga, queima”. O rapaz complementa: “(...) o ouro é como um fogo - corre, e depois, some feito fumaça”. Movimento é também o que se espera da riqueza obtida no garimpo. A este respeito os garimpeiros não indígenas afirmam que a fortuna súbita pode trazer infelicidade e que a riqueza conquistada no garimpo deve ser gasta o mais rapidamente possível. Ou seja, se o ouro se movimenta, os ganhos obtidos com ele também não devem, idealmente, ser retidos ${ }^{44}$. Slater demonstra que “(...) a única esperança de um homem de reter sua riqueza é gastar o dinheiro o mais rápido possível de maneira ostensiva e completamente pública” (1994, p. 727). Segundo a autora, gastar o que se ganha é uma via para se ganhar mais, ainda que não haja garantia quanto a isso. Entretanto, se houver apego à riqueza encontrada e aos ganhos dela provenientes, o garimpeiro certamente ficará mais pobre do que quando começou ${ }^{45}$.

Outro tema comum a várias das narrativas ouvidas pela pesquisadora na Amazônia brasileira e referentes à possibilidade de encontrar ouro é a morte, que surge, sobretudo nas histórias de "encantados" ou "mães", as quais possuem, pelo menos parcialmente, segundo Slater, raízes ameríndias. ${ }^{46} \mathrm{Em}$ ambas as acepções, associa-se o ouro a forças animais e/ou naturais, de onde viria uma suposta atração por sangue humano. Nas palavras de um garimpeiro, "o sangue chama o ouro". Este é uma via pela qual a morte adentra no universo do sucesso no garimpo: "se alguém é assassinado no buraco do ouro, esse buraco quase sempre produz mais ouro" (Slater 1994, p. 731). No entanto, essas mortes devem ocorrer segundo condições específicas. Não se pode matar, por exemplo, por ganância ou tendo em mente o ouro encontrado ou cuja descoberta foi relatada por alguém. Se assim o for, o ouro desaparece. Um garimpeiro disse a Slater (ibid.) que, “(...) se alguém mata só por matar, então, sim, [o ouro] pode aparecer”.

\section{Há uma distância segura?}

Os pensamentos e conhecimentos explicitados acima - Yanomami, Waiãpi, Baniwa, Tariano e de garimpeiros não indígenas - são passíveis de comparações. Meu argumento aqui vai no sentido de que uma primeira comparação entre essas diferentes perspectivas diz respeito à distância que se deve ter (ou não) em relação ao ouro e, eventualmente, também dos ganhos provenientes de sua extração e comercialização. Para os Yanomami, por exemplo, o ouro é intocável. Dada sua natureza de "antialimento patogênico", de "matéria quente e perigosa" (Albert, 1995), o ouro deve ser mantido com outros minérios embaixo da terra. De sua manutenção nos locais que lhes foram destinados pelo criador do mundo depen- gerar quanto de tirar vida de humanos e de animais e plantas" (Vianna, 2012, p. 124). Um interlocutor baniwa disse a Vianna, por exemplo, que "as pedras, elas também são vivas (...) são gente como nós. Mas para nós aqui, assim, no nosso olhar eles são pedras que não se mexem, que não fazem nada, mas para elas não. As pedras se sentem vivas" (ibid., p. 126-7). Ou seja, yóopinai é uma categoria ontológica e também relacional, no sentido de que se é yóopinai em relação a algo ou alguém. E, frise-se, trata-se de "relações estabelecidas entre mundos distintos, aproximando perspectivas de maneira inadequada e perigosa" (ibid., p. 128). Aliás, poderes cósmicos, durabilidade, ausência de periodicidade e um modo específico de ser da terra são qualidades relacionadas ao estatuto da "pedra" em outras partes das terras baixas sul-americanas, como apontado por Lévi-Strauss (2006, p. 358, 364-65), e também por Hugh-Jones (2012, p. 151), para ficar em apenas alguns exemplos. De outro lado, há outros modos pelos quais as pedras estão presentes nos arcabouços ontológicos de povos originários. Santos-Granero (1998), por exemplo, analisa a história contado por meio de formações rochosas (e na paisagem como um todo) em território Yanesha. Hugh-Jones (2012) examina, a partir da densidade de petróglifos na área do Alto Rio Negro, a compreensão sofisticada que os povos desta localidade têm de escrever narrativas e mitos na pedra. 36 Michael Taussig (2010) analisa cenário muito semelhante nas minas de prata na Bolívia, onde resiste a ideia de que se deve trocar o ouro ou outros minerais por vidas humanas com certos seres donos do metal, minério ou das serras. 37 Nascido na Itália, em 1852, Ermanno Stradelli iniciou suas expedições pela Amazônia em 1879, tendo percorrido ao longo de sua vida (até 1926) os rios Purus, Juruá, Uaupés, Apapóris e Jauaperi. Publicou diversos livros com narrativas e 
de a perpetuação deste e da humanidade. Há, neste discurso xamânico crítico Yanomami, um conteúdo que enfatiza a natureza material do ouro, o que ele é, a negatividade da potência que lhe é intrínseca e que é acionada quando o mesmo é extraído, seja como e por quem for.

Já para os Waiãpi, ouro seria minério semitocável, pois na concepção deste povo, suas características guardam certa ambiguidade. Foi o ouro, juntamente com outros minérios, que conferiram ao mundo sua solidez e a possibilidade de vida na Terra. Sua retirada, porém, não é interditada, mas deve ser realizada com o devido cuidado e por determinado tipo de gente. Aqui, a ideia de que pode haver consequências desastrosas decorrentes da extração do ouro tem mais a ver com as relações que esta atividade pode engendrar do que com a materialidade e/ou os ganhos provenientes de sua extração. Assim, o ouro pode ser cuidadosamente retirado de seus locais pelos Waiãpi e não pelos não indígenas, pois são os Waiãpi os responsáveis pelo território onde não somente está o ouro, mas onde estão inúmeras espécies de plantas, animais e demais seres, um território onde todos estão em relação.

A mesma condição de semitocável parece ocorrer, sob outras condições, no noroeste amazônico, onde se sabe que sendo o ouro matéria viva que tem "alma" e "dono", sua manipulação e eventual extração deve ser negociada com estes seres. No noroeste amazônico, o ouro não parece ser elemento tão central na composição material da Terra (como é para os Waiãpi) nem exclusivamente patogênico (como é para os Yanomami). O que torna as possibilidades de sua extração na região mais complexas, entretanto, é a própria condição interétnica da região (antes mesmo da emergência das relações com os não indígenas).

No Alto Rio Negro, além das negociações com os "donos" do ouro, há que se negociar com os "donos dos territórios", os quais, frequentemente, podem ser de outras etnias. A atual ocupação da região é fruto de deslocamentos que remontam aos tempos míticos e continuam a ocorrer até os dias de hoje. Ou seja, a presença de um determinado povo em uma dada porção territorial é justificada histórica e miticamente. Some-se a isso que o ouro costuma ocorrer em cavernas e morros que são também centros cosmológicos ${ }^{47}$, lugares tanto importantes quanto perigosos. Se esses lugares pertencem a seres como onças, por exemplo, o conhecimento dos caminhos até esses lugares e dos cuidados que se deve ter ao frequentá-los não é compartilhado por todos os povos da região, nem sequer por todos os membros de um mesmo povo, o que faz com que não haja um pensamento único para toda um grupo a respeito do ouro e dos lugares onde ele pode ser encontrado. $\mathrm{E}$ assim, a distância ou proximidade em relação ao ouro e seus lugares dependem do povo, da família, do clã, do grupo político etc. Nesse contexto, em que convivem diferentes grupos, as concepções acerca do ouro e sua extração também são múltiplas e, muitas vezes, geradoras de tensão e disputas. Assim, mais do que tocável ou intocável, o ouro é uma matéria com a qual a relação de determinado grupo passa por questões cosmológicas, políticas e éticas que conformam os domínios territoriais dos grupos que lá vivem.

Os quatro casos apresentados desenham uma espécie de gradiente, formulado a partir do controle de distâncias mais ou menos seguras das pessoas (humanas informações obtidas junto aos indígenas de diferentes povos com os quais conviveu, além de fotografias e gravuras.

38 Tariano é uma etnia de origem Aruak que passou por um processo de "tukanização", tendo adotado o tukano como língua (Andrello, 2004).

39 A tradução aproximada em tukano é Yamîri-wãtî (Barbosa; Garcia, 2000, p. 257). Wãtî, em tukano, é traduzido para o português por "diabo", designando um "modo de existência espiritual - trata-se tanto de um espectro das pessoas mortas como refere-se aos perigosos seres que habitam as florestas e serras e aos espíritos ancestrais que propiciavam os rituais de iniciação masculina" (Andrello, 2004, p. 233). Ver também C. Hugh-Jones (1979, p. 113).

400 que se sabe, a respeito de sua morte, é que Stradelli passou os últimos meses de vida em um leprosário em Manaus.

41 Como argumenta De Theije (2008), a mineração de ouro é, para os garimpeiros não indígenas, tanto ocupação quanto estilo de vida e está associado a um imaginário de bem-estar, sorte, riqueza súbita, mas também trabalho duro e consumo conspícuo, ou seja, que deve ser visível e facilmente notável (ver também De Boeck, 1998).

42 Sua pesquisa foi realizada nos estados de Roraima, Rondônia, Pará, Maranhão, Mato Grosso, Goiás e também na Guiana Francesa (Slater, 1994). 43 Gabriel Banaggia (2015) mostra como, para os garimpeiros da Chapada Diamantina (Bahia, nordeste brasileiro), os diamantes têm vida e se movimentam autonomamente, devendo, portanto, ser caçados e não coletados.

44 De Theije também salienta a capacidade do ouro de se movimentar: "A independência do ouro significa que ele pode se mover se não quer ser encontrado por determinado garimpeiro. Existem inúmeras histórias sobre o ouro encontrado por garimpeiros 
e não humanas) em relação ao ouro e entre os diferentes seres envolvidos nas atividades garimpeiras. Eles mostram que as concepções acerca do ouro que há na terra e sua extração não são de modo algum monolíticas e que outros modos de pensar este metal, seus usos, sua extração, são possíveis. ${ }^{48}$

Para os garimpeiros não indígenas, o ouro é tocável sob as condições de uma espécie de "troca parcimoniosa". Como nas outras perspectivas, aqui a morte reaparece, assumindo, porém, um caráter quase sacrificial. O ouro em si é absolutamente tocável, desejável, extraível, negociável, desde que assumidos os riscos dessas relações. O menor risco parece ser negociar com "almas penadas", o maior seria ter de matar e/ou morrer. Mas, alguma relação com a morte e/ou o sangue é necessária. A diferença em relação às perspectivas indígenas é que estas atividades não parecem envolver riscos de "morte do mundo" ou de outros seres que não sejam os humanos. A hipótese é de que essa ausência de preocupação ambiental ou vital na perspectiva dos garimpeiros não indígenas se deve ao fato de que esta atividade é vista mais como produtiva do que como destrutiva, o que está na contramão das perspectivas indígenas, que parecem concordar entre si nas críticas às relações produzidas a partir do ouro, as quais são tensas, potencialmente disruptivas, violentas, destrutivas e improdutivas. Em tempos de tragédias ambientais e sociais decorrentes de empreendimentos minerários e de investidas inescrupulosas sobre as terras e territórios indígenas visando às riquezas minerais que neles existem, é preciso estar atento também a essas perspectivas e críticas locais.

Recebido: 10/05/2019

Aprovado: 14/10/2019 em um local, onde depois os garimpeiros foram expulsos por algum motivo, somente para o agressor descobrir que o ouro não estava mais lá" (De Theije, 2008, p. 76).

$45 \mathrm{Em}$ pesquisa realizada com garimpeiros brasileiros no Suriname, De Theije também aborda as diversas crenças que existem em relação à natureza do ouro e como se faz para encontrá-lo. Segundo a autora, "o ouro não é um mineral facilmente encontrado, não se encontra prosperidade sem esforço. É preciso "fazer ouro". Mais que isso, mesmo quando há muito esforço, o sucesso não é garantido" (De Theije, 2008, p. 75).

46 "Encantados" definidos por Slater como seres que habitam a água e que podem se metamorfosear à vontade de criaturas aquáticas em seres humanos. Já as "mães" são forças naturais incorporadas e espíritos tutelares.

47 Como aponta Marques, a partir dos Hupd’äh: "essas cidades de localização difusa na periferia de /nih s'ah/tornam-se uma espécie de centro alternativo do mundo, os perigos e a potência patogênica a ela associados passam a conviver com outros aspectos [...]" (2015, p. 168). Para uma descrição da Serra Grande-Metrópole dos Hupd'äh, localidade que é reconhecidamente rica em recursos minerais por diversos povos na região, mas que é também local sagrado, e, por isso mesmo, repleto de perigos e cuidados, ver também Ramos (2018). 48 Distanciando-nos do escopo deste artigo poderíamos incluir neste ingrediente a empresa mineradora e a mineração de larga escala, envolvidas em processos nos quais não há negociações necessárias com seres (humanos e não humanos) e ambientes. Quanto a isso, ver também Kirsch (2014). Poderíamos avançar ainda na reflexão sobre os modos de se classificar o ouro também após sua extração, se ele entraria na chave da dádiva ou da mercadoria, ou ainda, em ambas (Gregory, 1982). 


\section{Referências}

ALBERT, Bruce. O ouro canibal e a queda do céu: uma crítica xamânica da economia política da natureza. Brasília: UnB, 1995. (Série Antropologia, 174).

ALBERT, Bruce; KOPENAWA, Davi. A queda do céu. São Paulo: Companhia das Letras, 2015.

AMORAS, W. W. A garimpagem na Amazônia: doenças, desordem e descaso, uma visão do garimpo do Crepori (PA). Dissertação (Mestrado no Núcleo de Altos Estudos Amazônicos) - Universidade Federal do Pará, Belém, 1991.

ANDRELLO, Geraldo. lauaretê: transformações sociais e cotidiano no rio Uaupés (Alto Rio Negro, Amazonas). Tese (Doutorado em Antropologia Social) - Universidade Estadual de Campinas, Campinas, 2004.

ANDRELLO, Geraldo. Política indígena no rio Uaupés: Hierarquia e Alianças. Teoria \& Pesquisa: Revista de Ciência Política, v. 17, n. 2, p. 75-91, 2008.

BALLARD, Chris; BANKS, Glenn. Resource wars: the anthropology of mining. Annual Reviews Anthropology, v. 32, p. 287-313, 2003.

BANAGGIA, Gabriel. As forças do Jarê: religião de matriz africana da Chapada Diamantina. Rio de Janeiro: Garamond, 2015.

BARBOSA, M. M.; GARCIA, A. M. Upíperi Kalísi: Histórias de antigamente. São Gabriel da Cachoeira, AM: FOIRN; lauaretê, AM: Unirva - União das Nações Indígenas do Rio Uaupés Acima, 2000. (Coleção Narradores Indígenas do Rio Negro, v. 4).

BARRETO FILHO, Henyo Trindade. A terra indígena como objeto de análise antropológica. Anuário Antropológico, v. 98, p. 233-246, 2002.

BERNSTEIN, Peter L. The power of gold: The history of an obsession. New York: Wiley, 2000.

BURKHALTER, S. B. Amazon Gold Rush, Markets and the Mundurucu Indians. Tese (Doutorado em Filosofia) - Columbia University, New York, 1982.

CALÓGERAS, João Pandiá. As minas do Brasil e sua legislação. Rio de Janeiro: Impressa Nacional, 1904.

CARNEIRO FILHO, Arnaldo; BRAGA DE SOUZA, Oswaldo. Atlas de pressões e ameaças às terras indígenas na Amazônia brasileira. São Paulo: Instituto Socioambiental, 2009.

CASCAES, D.; OLIVEIRA, M. C. C. Meio Ambiente do Pará: fato e norma. Belém: Numa/ UFPA, 1993.

CAVALCANTE, Thiago Leandro Vieira. "Terra Indígena": aspectos históricos da construção e aplicação de um conceito jurídico. História, v. 35, e. 75, 2016.

CLEARY, David. A garimpagem de ouro na Amazônia: uma abordagem antropológica. Rio de Janeiro: Ed. Da UFRJ, 1992. [Edição original: 1990].

CLEARY, David. Small-scale gold mining in Brazilian Amazonia. In: HALL, Anthony (Org.). Amazonia at the crossroads: the challenge of sustainable development. London: Institute of Latin American Studies, 2000.

COPPOLA, M. Gold Rush in Brazil. In: Randol at Vancouver '94 - Latin America Mining Opportunities. Vancouver, BC, Canada, Oct 31-Nov. 2, 1994.

COSTA, Francisco. "Nem tudo no ouro reluz": considerações para uma economia política da garimpagem na fronteira amazônica. In: MATHIS, Armin; REHAAG, Regine. Consequências da garimpagem no âmbito social e ambiental da Amazônia. Belém: Buntstft, FASE, Katalyse, 1993. 
CURI, Melissa Volpato. Aspectos legais da mineração em terras indígenas. Revista de Estudos e Pesquisas, FUNAI, v. 4, n. 2, p. 221-252, 2007.

DA SILVA, M. A. R. Mineração no Pará: elementos para uma estratégia de desenvolvimento regional. Belém: Governo do Estado do Pará, Secretaria de Estado e Indústria, Comércio e Mineração, 1994.

DE BOECK, Filip. Domesticating diamonds and dollars: Identity, expenditure and sharing in southwestern Zaire (1984-1997). Development and Change, v. 29, n. 4, p. 777-810, 1998.

DE THEIJE, Marjo. Ouro e Deus: sobre a relação entre prosperidade, moralidade e religião nos campos de ouro do Suriname. Religião e Sociedade, v. 28, n. 1, p. 69-83, 2008.

DIMENSTEIN, G. Meninas da Noite: a prostituição de meninas escravas no Brasil. São Paulo: Ática, 1992.

DOS SANTOS, Breno Augusto. Recursos Minerais da Amazônia. Estudos Avançados, v. 16, n. 45, p. 123-152, 2002.

DOUROJEANNI, Marc Jean; PÁDUA, Maria Tereza Jorge. Arcas à deriva: unidades de conservação no Brasil. Rio de Janeiro: Technical Books, 2013.

FIGUEIREDO, Lucas. O Tiradentes: uma biografia de Joaquim José da Silva Xavier. São Paulo: Companhia das Letras, 2018.

GALLOIS, D. T. Os Waiãpi e os garimpos. In: Aconteceu Especial Povos Indígenas no Brasil 1985, PIB-CEDI, São Paulo, 1985.

GALLOIS, D. T. O discurso waiãpi sobre o ouro - um profetismo moderno. Revista de Antropologia, v. 30/32, p. 457-467, 1989.

GALLOIS, D. T. L'or et la boue: cosmologie et orpaillage waiãpi. Ethnies, Paris, 1991.

GALLOIS, D. T. Jane Karakuri: o ouro dos Waiãpi, a experiência de um garimpo indígena. In: MAGALHÃES, A. C. (Ed.). Sociedade indígena e transformações ambientais. Belém: Universidade Federal do Pará, Núcleo de Meio Ambiente, 1993.

GARNELO, Luiza. Poder, hierarquia e reciprocidade: os caminhos da política e da saúde no Alto Rio Negro. Tese (Doutorado em Antropologia Social) - Universidade Estadual de Campinas, Campinas, 2002.

GODOY, R. Mining: anthropological perspectives. Annual Review of Anthropology, v. 14, p. 199-217, 1985.

GOODY, Jack. Metals, culture and capitalism: an essay on the origins of the modern world. New York: Cambridge University Press, 2012.

GREGORY, C. A. Gifts and Commodities. Nova lorque: Academic Press Inc., 1982.

GUEDES, André Dumans. Andança, agitação, luta, autonomia, evolução: sentidos do movimento e da mobilidade. Ruris, v. 9, n. 1, p. 111-141, 2015.

HART, Matthew. Gold: the race for the world's most seductive metal. New York: Simon; Schuster, 2013.

HUGH-JONES, C. From the Milk-River: Spatial and temporal processes in Northwest Amazonia. Cambridge: Cambridge University Press, 1979.

HUGH-JONES, Stephen. Escrever na pedra, escrever no papel. In: ANDRELLO, G. (Org.). Rotas de criação e transformação: narrativas de origem dos povos indígenas do Rio Negro. São Paulo: Instituto Socioambiental; São Gabriel da Cachoeira: Federação das Organizações Indígenas do Rio Negro, 2012. p. 138-167.

IUBEL, Aline F. Transformações políticas e indígenas: movimento e prefeitura no Alto 
Rio Negro. Tese (Doutorado em Antropologia Social) - Universidade Federal de São Carlos, São Carlos, 2015.

KIRSCH, Stuart. Mining capitalism: the relationship between corporations and their critics. California: University of California Press, 2014.

LABORATÓRIO DE ANTROPOLOGIAS DA T/terra. EntreTerras, v. 1, n. 1, 2017.

LEROY, Jean Pierro; MALERBA, Julianna. IIRSA, energia e mineração: ameaças e conflitos para as terras indígenas na Amazônia Brasileira. Rio de Janeiro: Fase, 2010.

LESTRA, Alain; NARDI, José. O Ouro da Amazônia Oriental: o mito e a realidade. Belém PA: Gafisa, 1984.

LÉVI-STRAUSS, Claude. A origem dos modos à mesa (Mitológicas v. 3). São Paulo: Cosac Naify, 2006.

LUCIANO, Gersem José dos Santos. "Projeto é como branco trabalha; as lideranças que se virem para aprender e nos ensinar": experiências dos povos indígenas do Alto Rio Negro. Dissertação (Mestrado em Antropologia Social) - Universidade de Brasília. Brasília, 2006.

MACMILLAN, Gordon. At the end of the rainbow? Gold, land and people in the Brazilian Amazon. London: Earthscan, 1995.

MARQUES, Bruno Ribeiro. Os Hupd'äh e seus mundos possiveis: transformações espaço-temporais do Alto Rio Negro. Tese (Doutorado em Antropologia Social) - Museu Nacional, Universidade Federal do Rio de Janeiro, Rio de Janeiro, 2015.

METAMIG - Metais de Minas Gerais. Ouro. 3. ed. Belo Horizonte. 222 p. 1981.

MINISTÉRIO DAS MINAS E ENERGIA. Informe Mineral do Estado do Pará. Brasília: Departamento Nacional de Produção Mineral, 1993.

MIRAS, Julia Trujillo, 2017. Demarcação e Equivocação: uma reflexão a partir do caso da Terra Indígena Krikati. R@U - Revista de Antropologia da UFSCar, v. 9, n. 1, p. 131-150.

PEREIRA, Alberto Carlos. Garimpo e fronteira amazônica: As transformações dos anos 80. In: UNA, Philippe; OLIVEIRA, Addilia (Org.). Amazônia: a fronteira agrícola 20 anos depois. Belém: Museu Paraense Emilio Goeldi. p. 305-318, 1991.

PERES, Sidnei Clemente. Cultura, política e identidade na Amazônia: o associativismo no Baixo Rio Negro. Tese (Doutorado em Antropologia Social). Campinas: Universidade Estadual de Campinas, 2003.

RAMOS, Danilo Paiva. A Caminho da Cidade das Onças: diálogos sobre os sonhos no percurso para a Serra Grande - Metrópole dos Hupd'äh. Revista de Antropologia, v. 61, n. 1, p. 329-359, 2018.

RIBEIRO, Berta. Os índios do rio Tiquié e o Projeto Calha Norte. CEDI-PIB, (mimeo.), 1987.

ROLLA, Alicia; RICARDO, Fany. Mineração em Terras Indígenas na Amazônia brasileira. São Paulo: Instituto Socioambiental, 2013.

SÁEZ, Oscar Calávia. O território, visto por outros olhos. Revista de Antropologia, v. 58, n. 1, p. 257-284, 2015.

SANTOS-GRANERO, Fernando. Writing history into the landscape: Space, Myth, and Ritual in Contemporary Amazonia. American Ethnologist, v. 25, n. 2, p. 128-148, 1998.

SILVA, A. R. B. Ouro do Pará: perdas técnicas, degradação e a marginalização do Estado na expansão industrial brasileira. Anais do XXXV Congresso Brasileiro de Geologia, 5: 2023-2030, Belém, 1988. 
SLATER, Candace. "All That Glitters": Contemporary Amazonian Gold Miners' Tales. Comparative Studies in Society and History, v. 36, n. 4, p. 720-742, 1994.

SOARES, Renato Martelli. Das Comunidades à Federação: Associações Indígenas do Alto Rio Negro. Dissertação (Mestrado em Antropologia Social) - Universidade de São Paulo, São Paulo, 2012.

SOUZA FILHO, Carlos; ARBOS, K. A jurisprudência internacional sobre mineração em Terras Indígenas: uma análise das decisões da Corte Interamericana de Direitos Humanos. Revista da Faculdade de Direito da UFG, v. 35, n. 1, p. 9-40, 2011.

TAUSSIG, Michael. O diabo e o fetichismo da mercadoria na América do Sul. São Paulo: Ed. da UNESP, 2010.

TEPASKE, John J. A new world of gold and silver. Leiden; Boston: Brill, 2010.

USOS e aplicações de Terras Raras no Brasil: 2012-2030. Brasília: Centro de Gestão e Estudos Estratégicos, 2013.

VALLE, Raul Silva Telles do; BATISTA, Fernando; PINHEIRO, Carolina Martins, 2013. Parecer jurídico sobre o APL de mineração em terras indígenas. In: ROLLA, A.; RICARDO, F. (Orgs.). Mineração em Terras Indígenas na Amazônia Brasileira 2013. São Paulo: Instituto Socioambiental, 2013.

VIANNA, João Jackson Bezerra. De volta ao caos primordial: alteridade, indiferenciação e adoecimento entre os Baniwa. Dissertação (Mestrado em Antropologia Social) - Universidade Federal do Amazonas, Manaus, 2012.

VILLAS BÔAS, Hariessa C. Mineração em terras indígenas: a procura de um marco legal. Rio de Janeiro: CETEM / MCT / CNPq / CYTED/IMPC, 2005.

WANDERLEY, L. Geografia do Ouro na Amazônia Brasileira: uma análise a partir da porção regional. Tese (Doutorado em Geografia) - Universidade Federal do Rio de Janeiro, Rio de Janeiro, 2015.

WANDERLEY, L. Ouro como moeda, ouro como commodity. Revista de Economia Política e História Econômica, n. 34, p. 5-47, 2015a.

WRIGHT, Robin. Uma política de dividir-e-conquistar: os Baniwa, a Mineração e o Projeto Calha Norte. Texto apresentado no 13 Encontro Anual da ANPOCS, GT de Política Indigenista. Caxambu-MG, 1989.

WRIGHT, Robin. História Indígena e do Indigenismo no Alto Rio Negro. Campinas-SP: Mercado de Letras; São Paulo: Instituto Socioambiental, 2005.

ZHOURI, Andréa. Anthropology and knowledge production in a "minefield". Vibrant, Virtual Brazilian Anthropology, v. 14, n. 2, 2017.

ZHOURI, Andréa (Org.). Mineração: violências e resistências: um campo aberto à produção de conhecimento no Brasil. Marabá, PA: Editorial iGuana; ABA, 2018. 